University of Nebraska - Lincoln

DigitalCommons@University of Nebraska - Lincoln

Papers in Natural Resources

Natural Resources, School of

2005

Discrete State-Space Approximation of the Continuous Kalinin-Milyukov-Nash Cascade of Noninteger Storage Elements

Jozsef Szilagyi

University of Nebraska-Lincoln, jszilagyi1@unl.edu

Follow this and additional works at: https://digitalcommons.unl.edu/natrespapers

Part of the Natural Resources and Conservation Commons, Natural Resources Management and Policy Commons, and the Other Environmental Sciences Commons

Szilagyi, Jozsef, "Discrete State-Space Approximation of the Continuous Kalinin-Milyukov-Nash Cascade of Noninteger Storage Elements" (2005). Papers in Natural Resources. 979.

https://digitalcommons.unl.edu/natrespapers/979

This Article is brought to you for free and open access by the Natural Resources, School of at DigitalCommons@University of Nebraska - Lincoln. It has been accepted for inclusion in Papers in Natural Resources by an authorized administrator of DigitalCommons@University of Nebraska - Lincoln. 
See discussions, stats, and author profiles for this publication at: https://www.researchgate.net/publication/222432942

Discrete state-space approximation of the continuous Kalinin-MilyukovNash cascade of noninteger storage elements

Article in Journal of Hydrology · August 2006

DOl: 10.1016/j.jhydrol.2005.12.015

\section{CITATIONS}

6

1 author:

Joe Szilagyi

Budapest University of Technology and Economics

104 PUBLICATIONS 1,847 CITATIONS

SEE PROFILE

Some of the authors of this publication are also working on these related projects:

The Complementary Relationship in Land Surface Evapotranspiration View project 


\title{
Discrete state-space approximation of the continuous Kalinin-Milyukov-Nash cascade of noninteger storage elements
}

\author{
Jozsef Szilagyi
}

Conservation and Survey Division, Institute of Agriculture and Natural Resources, University of Nebraska-Lincoln, 113 Nebraska Hall, Lincoln, NE 68588-0517, United States

Received 14 April 2005; received in revised form 21 November 2005; accepted 4 December 2005

\author{
KEYWORDS \\ Stream-flow; \\ Flow routing; \\ Hydrologic model; \\ Discrete linear \\ cascade model
}

\begin{abstract}
Summary A generalization of the discrete linear cascade model (DLCM), which is a statespace-formulated discretized version of the continuous Kalinin-Milyukov-Nash Cascade, is described for noninteger number of uniform storage elements. The generalized model was tested against numerically integrated values of the Saint-Venant equations and was found to yield improved model accuracy in comparison with the traditional uniform cascade of integer number of storage elements. The storage coefficient of the last reservoir can be specified independently of that of the rest of the cascades, which makes the present model better suited for flow routing over reaches where the target gauging station is found near sudden changes in channel properties.
\end{abstract}

(C) 2005 Elsevier B.V. All rights reserved.

\section{Introduction}

Somewhat contrary to intuition, flow routing techniques, which are based on simplifications of the Saint-Venant equations of open channel flow, are still in use worldwide in the 21st century. This happens even though personal computers are widespread and their computational power is on par with the supercomputers used just 20 years ago. There are, however, several reasons why these approximate techniques are still used in place of numerically integrating the Saint-Venant equations for open channel flow problems, and

E-mail address: jszilagyi1@unl.edu. more specifically, for the purpose of operational streamflow forecasting. Typically, these are: (a) lack of information on the geometry of the channel and associated floodplains; (b) lack of correct (looped) rating curves, or; (c) in extreme, but probably not rare, cases, the lack of any discharge measurements. On the other hand, most flow routing techniques: (a) do not require information on the channel and floodplain geometry; (b) require only simplified (i.e. nonlooped) rating curves; (c) are linear in nature, which is fortunate for the propagation of errors in the stage and discharging values, and; (d) as long as the routing method is linear, it can even be used without discharge (but including stage) measurements as was demonstrated by Szilagyi et al. (2005). 
Among the profusion of available flow routing techniques (e.g. Camacho and Lees, 1999; Keefer and McQuivey, 1974; Kontur, 1977; Kundzewicz and Dooge, 1985; O'Connor, 1976; Perumal, 1994; Szolgay, 1991, 2004), the discrete linear cascade model (DLCM) (Szollosi-Nagy, 1982, 1989; Szilagyi, 2003, 2004; Szilagyi et al., 2005) stands out for several reasons: (a) it is equivalent to the discretized form of the continuous, spatially discrete, kinematic wave equation (Szollosi-Nagy, 1989); (b) it is specifically formulated to deal with discrete data whether in a pulse- or sample-data system framework; (c) it is discretely coincident, which means that for identical inputs (as between the discrete and continuous models), it gives identical outputs at discrete time increments; (d) it does not require numerical iterations (so numerical stability is not an issue) because it is written in a state-space form with the state- and input-transition matrices given explicitly; (e) since it is in a state-space form, linear filtering techniques, such as the Kalman filter (1960), can directly be applied; and last but not the least, (f) with it, the inverse problem of finding the input sequence to a given output sequence (which often is needed to fill data gaps in a streamflow series) is a simple algebraic manipulation.

DLCM has been in operational use for the Danube and its tributaries, including 200-plus gauging stations, at the $\mathrm{Na}$ tional Hydrological Forecasting Service (NHFS) in Hungary for almost two decades and had a central role in flood defense works by providing authorities with information of when and at what level the floods will peak. It had gone through several revisions recently (e.g. Szilagyi, 2003, 2004) of which the present effort is the latest.

It has been long known from practice at NHFS that DLCM performed worse for certain reaches in comparison with modeling results obtainable when using a continuous cascade of noninteger number of equal storage elements. In this study, therefore, the objective is to bring the statespace description into a form that can approximate the continuous case of a fractional number of equal storage elements. To demonstrate that the so-derived model is viable, numerically integrated solutions of the Saint-Venant equations will be used as benchmark values in testing model simulations.

\section{State-space approximation of a uniform noninteger $n$-cascade of linear storage elements}

Kalinin and Milyukov's (1957) flow routing method assumes that a river section, with no lateral inflow, can be conceptualized as a series of characteristic reaches where the outflow $(Q)$ is a linear function of water stored $(S)$ within the reach. Kalinin and Milyukov (1958) derived that the impulse response, $h$ (or instantaneous unit hydrograph, IUH), a continuous function of time, $t$, of $n$ such equal characteristic reaches can be expressed as

$h(t)=k \frac{(k t)^{n-1}}{\Gamma(n)} \mathrm{e}^{-k t}$

where $k\left[T^{-1}\right]$ is the constant coefficient of the linear outflow-storage relationship

$Q(t)=k S(t)$ and $\Gamma$ is the complete gamma function defined as

$\Gamma(n)=\int_{0}^{\infty} \varsigma^{n-1} \mathrm{e}^{-\varsigma} \mathrm{d} \varsigma$

where $\varsigma$ is a dummy variable.

Nash (1957), independently of Kalinin and Milyukov, derived Eq. (1) for $n$ equal, serially connected linear reservoirs, each characterized by Eq. (2), for watershed response to effective precipitation.

Szollosi-Nagy $(1976,1981)$ formulated a state-space description of the continuous Kalinin-Milyukov-Nash $(\mathrm{KMN})$-cascade such as

$\underline{\dot{S}}(t)=\underline{F} \underline{S}(t)+\underline{G} u(t)$

where the dot denotes the temporal rate of change in the variable, $u\left[\mathrm{~L}^{3} \mathrm{~T}^{-1}\right]$ is the instantaneous inflow rate of the first characteristic reach or storage element, $\underline{S}$ denotes the vector of stored water volumes of the $n$ linear storage elements, $\underline{G}$ is the so-called input vector

$\underline{G}=[1,0, \ldots, 0]^{\prime}$

where the prime designates the transpose, and $\underline{F}$ is the $n \times n$ state or system matrix

$\underline{F}=\left[\begin{array}{ccccc}-k & & & & 0 \\ k & -k & & & \\ & k & -k & & \\ & & \ddots & \ddots & \\ 0 & & & k & -k\end{array}\right]$

The output equation yields the outflow rate $(Q)$ from the last storage element as

$Q(t)=\underline{H S}(t)$

where $\underline{H}=[0, \ldots, k]$.

The solution of Eq. (4) is given by (Szollosi-Nagy, 1982)

$\underline{S}(t)=\underline{\underline{\Phi}}\left(t, t_{0}\right) \underline{S}\left(t_{0}\right)+\int_{t_{0}}^{t} \underline{\underline{\Phi}}(t, \tau) \underline{G} u(\tau) \mathrm{d} \tau$

where

$\underline{\underline{\Phi}}\left(t, t_{0}\right)=\mathrm{e}^{\underline{F} \cdot\left(t-t_{0}\right)}$

is the $n \times n$ state-transition matrix

$\underline{\underline{\Phi}}\left(t, t_{0}\right)=\left[\begin{array}{cccc}\mathrm{e}^{-k\left(t-t_{0}\right)} & 0 & \cdots & 0 \\ k\left(t-t_{0}\right) \mathrm{e}^{-k\left(t-t_{0}\right)} & \mathrm{e}^{-k\left(t-t_{0}\right)} & \cdots & \vdots \\ \vdots & \ddots & \ddots & 0 \\ \frac{\left[k\left(t-t_{0}\right)\right]^{n-1}}{(n-1) !} \mathrm{e}^{-k\left(t-t_{0}\right)} & \cdots & k\left(t-t_{0}\right) \mathrm{e}^{-k\left(t-t_{0}\right)} & \mathrm{e}^{-k\left(t-t_{0}\right)}\end{array}\right]$

Note that the IUH of Eq. (1) for an integer value of $n$ is recaptured as $k$ times the last element of the first column of $\Phi$, provided $t_{0}=0$ is chosen.

$\overline{\bar{N}}$ ash suggested (Dooge, 1973) that in practical applications $n$ should be allowed to take noninteger values in Eq. (1). The state-space description, however, can only consider an integer number of storage elements. This way, with the state-space approach, one can only approximate the IUH (Eq. (1)) of the general continuous noninteger $n$-value case. 
The IUH of a fractional storage element, i.e. when $n<1$, is also given by Eq. (1). In the state-space formulation, a trivial choice for a constant storage coefficient when $x=n<1$ can be

$k_{x}=\frac{k}{x}$

since the mean storage time is $k^{-1}$, which is expected to be smaller for a fractional storage element than for a full one (i.e. when $n=1$ ). With this constant coefficient approximation a fractional storage element will behave as a full one with a magnified $k$ value. This observation also means, that the uniform fractional $n$-cascade of Eq. (1) can be represented in the state-space approach by replacing the last storage element in the cascade with an element whose storage coefficient is $k_{x}=k[n-\operatorname{int}(n)]^{-1}$, where int designates the integer part of $n$. As a simplifying convention, the fractional element must always be the last one in the cascade, ensuring that only the last row of the system matrices is different from the case of a uniform cascade. Note that the order of the unequal storage elements is otherwise irrelevant, since any ordering results in the same output due to linearity (Dooge and O'Kane, 2003, pp. 60).

The new $n^{*} \times n^{*}$ [where $\left.n^{*}=\operatorname{int}(n+1)\right]$ system matrix, $\underline{\underline{F}}$, will remain unchanged in its $\operatorname{int}(n) \times \operatorname{int}(n)$ dimension, but its last row/column will be changed

$$
\underline{F}=\left[\begin{array}{ccccc}
-k & & & & 0 \\
k & -k & & & \\
& k & -k & & \\
& & \ddots & \ddots & \\
0 & & & k & -\frac{k}{x}
\end{array}\right]
$$

where $x=n-\operatorname{int}(n)$. Determination of the new state-transition matrix, $\Phi$, can be achieved, e.g., by successive convolution. Note that unlike in the system matrix case, each element of the last row of $\underline{\underline{\Phi}}$ will be different. Performing the matrix exponential in Eq. (9) for small values of $n^{*}$ with the help of, e.g. the Maple software, one can deduce that the last row will contain the IUH's (divided by $k_{x}$ ) of nonuniform cascades of decreasing (by unity) dimension, similarly to the last row of $\underline{\underline{\Phi}}$ in Eq. (10) that contains the IUH's (divided by $k$ ) of integer uniform $n$-cascades. Note that $\Phi_{n^{*}, n^{*}}=\mathrm{e}^{-k_{x} t}$. It is sufficient to determine $\Phi_{n^{*}, 1}$, as

$\Phi_{n^{*}, 1}=\frac{1}{k_{x}} h(t)=\frac{1}{k_{x}} \int_{0}^{t} k \frac{(k \tau)^{n^{*}-2}}{\left(n^{*}-2\right) !} \mathrm{e}^{-k \tau} k_{x} \mathrm{e}^{-k_{x}(t-\tau)} \mathrm{d} \tau$

which, after some algebraic manipulation, yields

$$
\begin{aligned}
\Phi_{n^{*}, 1}= & \frac{k(k t)^{n^{*}-2} \mathrm{e}^{-k_{x} t}}{\left(n^{*}-2\right) !\left(k_{x}-k\right)} \cdot\left\langle\mathrm{e}^{\left(k_{x}-k\right) t}\right. \\
& \left.+\left\{\left[\left(k-k_{x}\right) t\right]^{2-n^{*}}\left[\left(n^{*}-2\right) \Gamma\left(n^{*}-2,\left(k-k_{x}\right) t\right)-\left(n^{*}-2\right) !\right]\right\}\right\rangle,
\end{aligned}
$$$$
n^{*} \geqslant 2 ; \quad k_{x} \neq k
$$

Here, the incomplete gamma function (i.e. with two arguments) is defined as

$\Gamma(\boldsymbol{n}, \boldsymbol{x})=\int_{x}^{\infty} \varsigma^{n-1} \mathrm{e}^{-\varsigma} \mathrm{d} \varsigma$

where again $\varsigma$ is a dummy variable. Note that when $n^{*}=2$ and $k_{x} \neq k$, one has a cascade of two unequal linear storage elements.
With discrete data at regular $\Delta t$ intervals, Eq. (8) becomes

$\underline{S}(t+\Delta t)=\underline{\underline{\Phi}}(t+\Delta t, t) \underline{S}(t)+\int_{t}^{t+\Delta t} \underline{\underline{\Phi}}(t+\Delta t, \tau) \underline{G} u(\tau) \mathrm{d} \tau$

which, in the pulse-data system framework, i.e., when inflow is assumed to be constant between subsequent discrete values (Chow et al., 1988), transforms into (Szollosi-Nagy, 1982)

$\underline{S}(t+\Delta t)=\underline{\Phi}(\Delta t) \underline{S}(t)+\underline{\Gamma}(\Delta t) u(t)$

where the input-transition vector, $\underline{\Gamma}(\Delta t)$, is defined as

$\underline{\Gamma}(\Delta t)=\int_{t}^{t+\Delta t} \underline{\underline{\Phi}}(t+\Delta t-\tau) \underline{G} \mathrm{~d} \tau$.

Each row of the input-transition vector for a uniform cascade contains the complementary (i.e. to Eq. (15)) and scaled (i.e. divided by the complete gamma function value) incomplete gamma function (further divided by $k$ ) with integer value of $n$ for its first argument. Thus, its ith component, using the Poisson distribution relationship (Abramowitz and Stegun, 1972, pp. 262), can be written as (Szollosi-Nagy, 1982)

$\Gamma_{i}(\Delta t)=\frac{1}{k}\left[1-\mathrm{e}^{-k \Delta t} \sum_{j=0}^{i-1} \frac{(k \Delta t)^{j}}{j !}\right]$

In the discrete-time case the input-transition vector, $\Gamma(\Delta t)$, of a uniform cascade is made up of the continuous unit-step-response functions, $g(t)$, of cascades of increasing order, with the $t=\Delta t$ substitution (Szollosi-Nagy, 1982). Note that for the state-transition matrix (Eqs. (10) (14)), the only difference between its continuous- and discrete-time forms is that in the latter case $\Delta t$ replaces $t$, provided $t_{0}=0$ is chosen. Note also that an input-transition vector cannot be defined (see Eq. (16)) unless the continuous input is pulsed or otherwise algebraic (e.g. linear). Eqs. (10) (with the $t-t_{0}=$ $\Delta t$ substitution), (17), and (19) comprise the original discrete linear cascade model (Szollosi-Nagy, 1982) for pulsed inputs.

In the nonuniform cascade case, the first int $(n)$ elements of the input-transition vector will again be the same as in the uniform cascade case. The last component of $\underline{\Gamma}(\Delta t)$ can be obtained, as before, through successive convolution

$$
\begin{aligned}
\Gamma_{n^{*}}(\Delta t) & =\frac{1}{k_{x}} g(\Delta t) \\
& =\frac{1}{k_{x}} \int_{t}^{t+\Delta t}\left[1-\mathrm{e}^{-k \tau} \sum_{j=0}^{n^{*}-2} \frac{(k \tau)^{j}}{j !}\right] k_{x} \mathrm{e}^{-k_{x}(t-\tau)} \mathrm{d} \tau
\end{aligned}
$$

which, after certain degree of algebraic manipulation, becomes

$$
\begin{aligned}
\Gamma_{n^{*}}(\Delta t)= & \frac{1-\mathrm{e}^{-k_{x} \Delta t}}{k_{x}}-\mathrm{e}^{-k_{x} \Delta t} \\
& \times \sum_{j=0}^{n^{*}-2}\left\langle\frac{(k \Delta t)^{j}}{\left(k_{x}-k\right) j !}\left\{\mathrm{e}^{\left(k_{x}-k\right) \Delta t}+\left[\frac{j \Gamma\left(j,\left(k-k_{x}\right) \Delta t\right)-j !}{\left[\left(k-k_{x}\right) \Delta t\right]^{j}}\right]\right\}\right\rangle \\
n^{*} \geqslant 2 ; \quad & k_{x} \neq k
\end{aligned}
$$

Eqs. (14) (with the $t=\Delta t$ substitution), (17), and (21) form the state-space approximation of a uniform fractional $n$-cascade written in a pulse-data system framework.

When modeling continuous physical systems using discrete data, a more realistic approach to the pulse-data 
system framework is to assume that the value of the continuous-input variable changes linearly between consecutive samples. This approach is called the sample-data system framework (Chow et al., 1988; Hantush et al., 2002). Szilagyi $(2003,2004)$ formulated the DLCM in such a framework. The state-transition matrix is the same in both the pulseand sample-data system frameworks, but not, however, the input-transition vector.

The input-transition vector separates into two vectors, one, $\Gamma_{1}(\Delta t)$, that operates on $u(t+\Delta t)$ and another, $\Gamma_{2}(\Delta t)$, that acts on $u(t)$. Note that for specifying a linear change, two observations are needed. In real-time operative forecasting, the input at time $t+\Delta t$ is typically the forecasted value (whether using another gauging stage further upstream or a rainfall-runoff model output) of the flowrate at the upstream location. In simulation experiments, it means that for obtaining a modeled value at the downstream location, one needs to specify the concurrent value at the upstream gauging station. Again, the first int $(n)$ elements of either input-transition vectors remain unchanged

$\Gamma_{1 i}(\Delta t)=\Gamma_{i}(\Delta t)-\frac{i}{k \Delta t} \Gamma_{i+1}(\Delta t) \quad i=1, \ldots, \operatorname{int}(n)$

and

$\Gamma_{2 i}(\Delta t)=\frac{i}{k \Delta t} \Gamma_{i+1}(\Delta t) \quad i=1, \ldots, \operatorname{int}(n)$

respectively. As before, the last component of the inputtransition vectors can be obtained through successive convolution. After some algebraic manipulations, the successive convolution yields the following expressions for the last component of the input-transition vectors:

$\Gamma_{1 n^{*}}(\Delta t)=\frac{\mathrm{e}^{-k_{x} \Delta t}}{\Delta t}\left[\alpha-\beta-\frac{n^{*}-1}{k} \Gamma_{n^{*}+1}(\Delta t)\right]$

and

$\Gamma_{2 n^{*}}(\Delta t)=\Gamma_{n^{*}}(\Delta t)-\Gamma_{1 n^{*}}(\Delta t)$

where

$\alpha=\frac{1+\mathrm{e}^{k_{x} \Delta t}\left(k_{x} \Delta t-1\right)}{k_{x}^{2}}$

$\beta=\sum_{j=1}^{n^{*}-1}\left\langle\frac{k^{j-1}(\Delta t)^{j}}{\left(k_{x}-k\right)(j-1) !}\left\{\mathrm{e}^{\left(k_{x}-k\right) \Delta t}+\left[\frac{j \Gamma\left(j,\left(k-k_{x}\right) \Delta t\right)-j !}{\left[\left(k-k_{x}\right) \Delta t\right]^{j}}\right]\right\}\right\rangle$

respectively.

Finally, in the output equation's (Eq. (7)) $\underline{H}$ vector $k_{x}$ will replace $k$ for the nonuniform $n^{*}$-cascade. Eq. (14) (with the $t=\Delta t$ substitution), as well as Eqs. (22)-(27) with the corresponding $u(t+\Delta t)$ and $u(t)$ values, specifies the state-space approximation of a uniform fractional $n$-cascade written now in a sample-data system framework.

It can be concluded that the closer the value of $n$ to an integer, the better the fit becomes between the uniform, fractional $n$-cascade of Eq. (1) and its approximate, statespace formulated nonuniform, integer $n^{*}$-cascade. Naturally, when $n$ is an integer the two models are discretely coincident. Similarly, the larger the integer part of $n$, the smaller the difference becomes between the two model outputs. As a consequence, the two models are expected to yield almost identical forecasts when $n$ is relatively large and/or when its value is close to an integer.
The importance of considering a fractional uniform cascade (and thus its nonuniform state-space approximation) is highlighted by the observation that in many practical applications, using flowrate values, the value of $n$ tends to remain small. This is so because for a given stream reach, represented by uniform linear storage elements, the mean storage delay time (also called residence or travel time), $T$, is $n k^{-1}$. As the value of $n$ is increased (while keeping $T$ constant), the response of the river reach becomes less and less diffusive. The observations of natural river channels of gentle slope (i.e. less than $0.01 \%$, characteristic of the Danube in Hungary) show a typically high degree of dispersion (i.e. the flood waves flatten out relatively fast), therefore leading to small optimized $n$ values. For small values of $n$, however, it makes a relatively large difference whether $n$ may assume only integer values or is allowed to have noninteger values as well during the optimization process.

Finally, specifying the system matrices for a discrete nonuniform cascade approximating a continuous uniform cascade of noninteger number of storage elements is necessitated by the fact that the discrete linear cascade model is not transitive, as was initially claimed by Szollosi-Nagy (1989). Transitivity would allow for taking the discrete output of a uniform $(n-1)$-cascade and subsequently routing it through an additional storage element and obtain the same result as when performing the task in one single step, thus obliviating the need of working out the system matrices of the nonuniform cascade case. This, however, is not so, simply, because the discrete model makes only assumptions on how the discretely observed input signal behaves between subsequent samples; consequently, this assumed behavior of the input signal is not identical with that of the original continuous signal. This way two different signals enter the last storage element in the above example; thus the output must also be different between the two cases (i.e. one-step or two-step approach). Consequently, the output of the discrete nonuniform $n$-cascade cannot be replicated by simply employing a discrete uniform $(n-1)$-cascade first and routing its output additionally through another storage element (of different storage coefficient).

\section{Model testing and conclusions}

Testing of the above described flow routing model's performance was achieved by numerically integrating the SaintVenant equations of open channel flow (e.g. Henderson, 1966) for obtaining "ground-truth" data over a rectangular channel of $2000 \mathrm{~km}=2 \times 10^{6} \mathrm{~m}$ in length, $B=300 \mathrm{~m}$ in width and a constant channel slope $S_{0}=0.0002$. The validation was achieved in two stages.

First, a constant Manning's roughness parameter value $n_{0}=0.035$ was used for the entire length of the channel. The upper boundary condition was prescribed by the following equations for the water depth, $h(x, t)$

$$
\begin{aligned}
h(x=0, t)= & h_{0}+\frac{1-\cos \left(\frac{2 \pi}{t_{m}} t\right)}{1-\cos \left(\frac{2 \pi}{t_{m}} t_{c}\right)} \\
& \times \exp \left[\frac{2 \pi}{t_{m}}\left(t_{c}-t\right) \cot \left(\frac{t_{c} \pi}{t_{m}}\right)\right] \quad 0 \leqslant t \leqslant t_{m} \\
h(x=0, t)= & h_{0} \quad t>t_{m}
\end{aligned}
$$


with $t_{\mathrm{m}}=2 d=172,800 \mathrm{~s}, t_{\mathrm{c}}=0.5 d=43,200 \mathrm{~s}$, and with an initial prescribed normal depth, $h_{0}=5 \mathrm{~m}$. The lower boundary condition was defined by the Manning-equation

$v\left(x=2 \times 10^{6}, t\right)=\frac{\sqrt{S_{0}}}{n_{0}} R^{2 / 3}=\frac{\sqrt{S_{0}}}{n_{0}}\left(\frac{h B}{B+2 h}\right)^{2 / 3}$

which yields a value of $1.156 \mathrm{~m} \mathrm{~s}^{-1}$ for the initial normal velocity, $v_{0}$. Here, $R$ is the hydraulic radius.

Flow routing calculations were performed at around the middle of the $2000 \mathrm{~km}$-long channel reach, i.e., between $900 \mathrm{~km}$ and $1000 \mathrm{~km}$. Such a choice minimizes the somewhat artificial nature of the upper and lower boundary conditions, since: (a) a real hydrograph rarely follows the exact

Table 1 Optimized values of the flow routing model and associated mean root-squared errors (MRSE) taken over the period of 46-162 h of Figs. 1 and 2: (a) uniform integer $n$ cascade, (b) uniform noninteger $n$-cascade approximated by a nonuniform $n^{*}$-cascade and (c) fully nonuniform (in the last storage element) cascade

\begin{tabular}{llll}
\hline & $(\mathrm{a})$ & $(\mathrm{b})$ & (c) \\
\hline$n_{0}=0.035$ & \multicolumn{3}{l}{$0.58(0.63)$} \\
$k_{\text {opt }},\left(k_{x}^{\text {opt }}\right)\left(\mathrm{h}^{-1}\right)$ & 0.515 & 0.58 & 0.581 \\
$n_{\text {opt }}$ & 7 & 7.91 & 7.91 \\
MRSE $\left(\mathrm{m}^{3} \mathrm{~s}^{-1}\right)$ & 3.28 & 2.55 & 2.55 \\
\multicolumn{4}{l}{} \\
$n_{0}=0.035 x<1000 \mathrm{~km}$, & $n_{0}=0.045 x \geqslant 1000 \mathrm{~km}$ \\
$k_{\text {opt }},\left(k_{x}^{\text {opt }}\right)\left(\mathrm{h}^{-1}\right)$ & 0.49 & 0.595 & $0.785(0.35)$ \\
$n_{\text {opt }}$ & 7 & 8.51 & 9 \\
MRSE $\left(\mathrm{m}^{3} \mathrm{~s}^{-1}\right)$ & 2.16 & 1.5 & 1.45 \\
\hline
\end{tabular}

shape described by Eq. (28); and (b) a functional relationship between depth and velocity, given by Eq. (29), is rarely the case for nonpermanent conditions. The flowrate values given by the Saint-Venant equations at regular $\mathrm{d} t=2 \mathrm{~h}$ intervals for $x=900 \mathrm{~km}$ served as the "observed" instantaneous upstream flow values for flow routing using a sample-data system framework.

In the first experiment, the number of linear storage elements, $n$, was allowed to assume only integer values. Optimization of $n$ and $k$ was achieved by trial-and-error, which involves systematically trying out the values of the parameters with predefined ranges and increment values. Once an optimum had been achieved in a mean root-squared sense with a given "resolution", a stricter range with a smaller increment value was used repeatedly for each parameter until the change in the mean root-squared error became negligible. Such an approach circumvents the application of arbitrary parameter optimization routines and can be considered as a "brute force" or direct optimization. The state-space model requires only pure algebraic manipulations, which lends itself suitable for such a direct optimization approach. The optimization results are displayed in Table 1, while the corresponding hydrographs are displayed in Fig. 1.

In the second experiment, $n$ was allowed to assume noninteger values during optimization (Table 1, Fig. 1). Note that in this case the storage coefficient value, $k_{x}$, of the last storage element must always be larger than unity due to Eq. (11). Finally, in the third experiment, the storage coefficient of the last linear storage element was allowed to take any value (i.e. fully nonuniform cascade case) by having it optimized independently of $n$ and $k$ of the rest of the

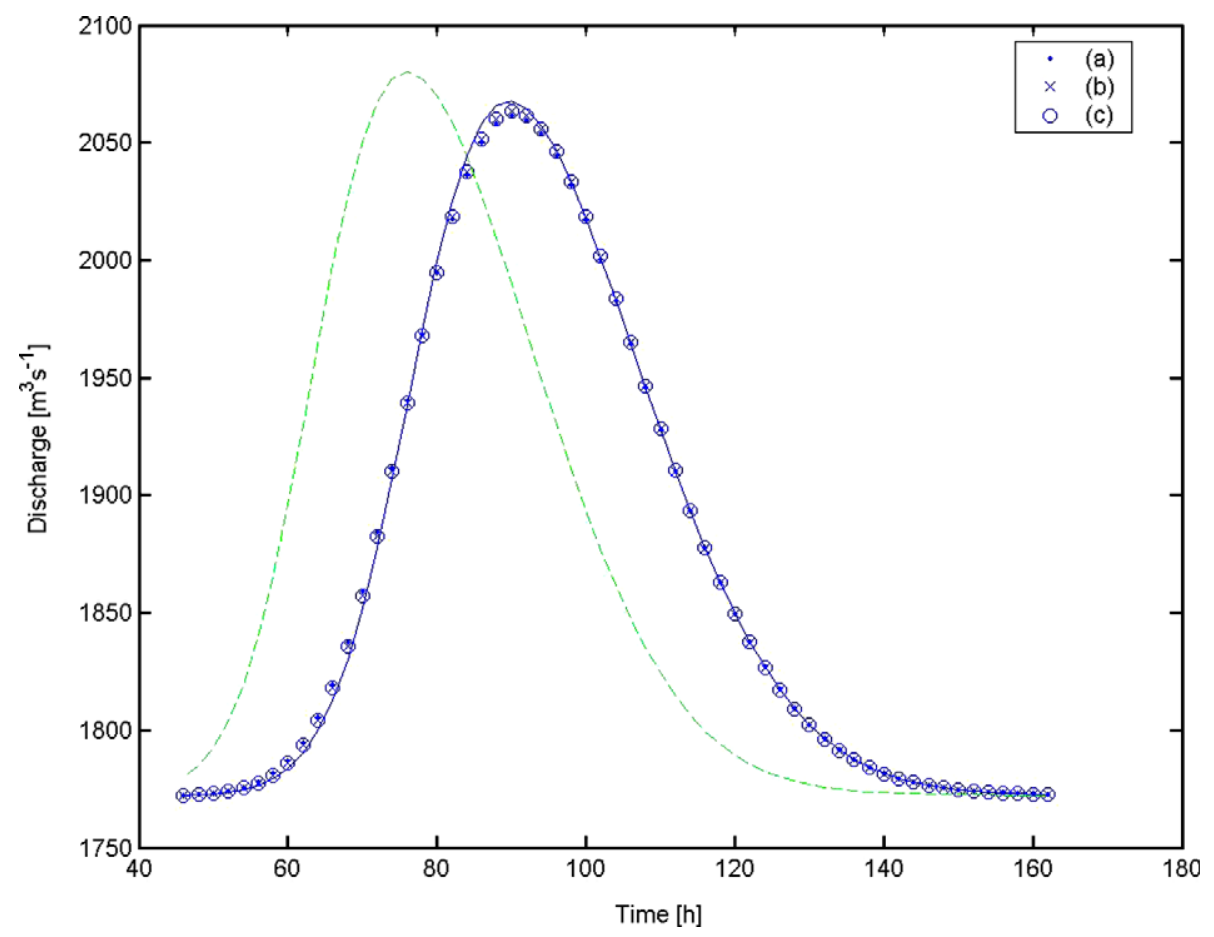

Figure 1 Up- (intermittent) and downstream (solid) discharge hydrographs for the flow routing channel reach (i.e. $900 \mathrm{~km} \leqslant x \leqslant 1000 \mathrm{~km}$ ), provided by the Saint-Venant equations; model results of: (a) uniform integer $n$-cascade, (b) uniform noninteger $n$-cascade approximated by a nonuniform $n^{*}$-cascade and (c) fully nonuniform cascade. $n_{0}=0.035$. Time origin is arbitrary. 
cascade (Table 1, Fig. 1). The idea behind it being that in the presence of any sudden change in channel properties (i.e. slope, roughness, etc.) near the end of a reach, the last storage element could respond faster or slower than that of the rest of the cascade. Note that in the discrete statespace representation of the uniform fractional $n$-cascade, the last storage element is always faster when comparing to the rest of the cascade.

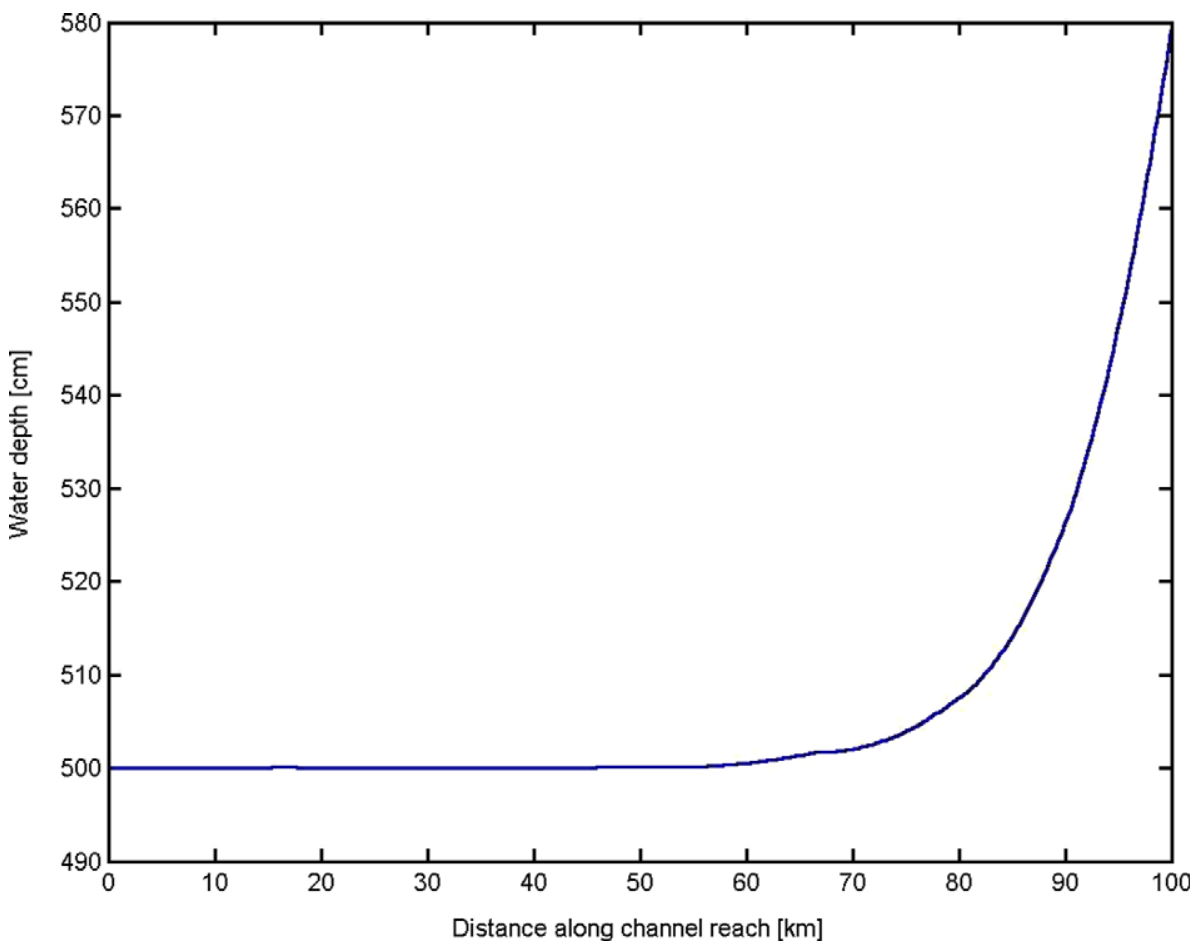

Figure 2 Normal depth, $h_{0}$, over the flow routing channel reach $(900 \leqslant x \leqslant 1000 \mathrm{~km})$ when the value of $n_{0}$ jumps at $x=1000 \mathrm{~km}$.

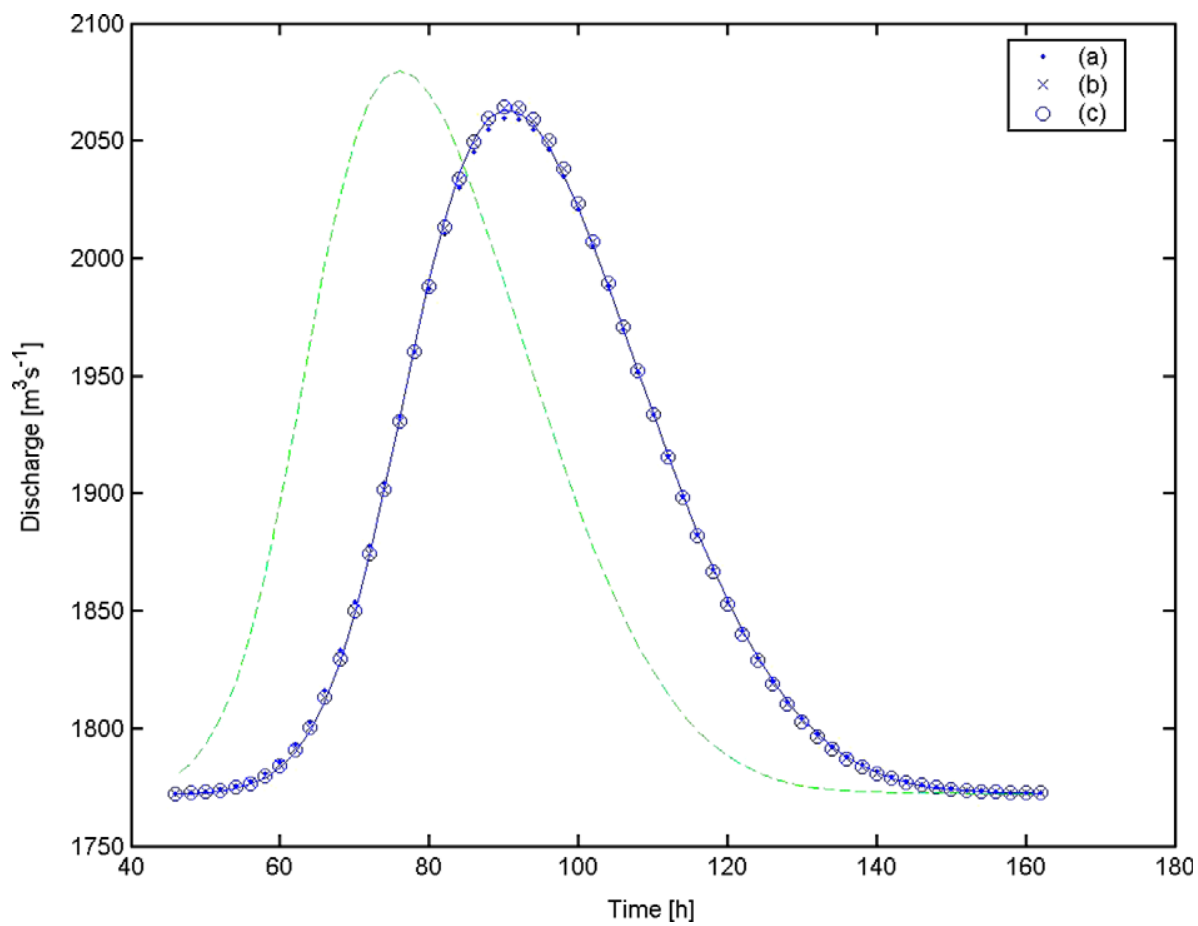

Figure 3 Up- (intermittent) and downstream (solid) discharge hydrographs for the flow routing channel reach (i.e. $900 \mathrm{~km} \leqslant x \leqslant 1000 \mathrm{~km}$ ), provided by the Saint-Venant equations; model results of: (a) uniform integer $n$-cascade, (b) uniform noninteger $n$-cascade approximated by a nonuniform $n^{*}$-cascade and (c) fully nonuniform cascade. $n_{0}=0.035$ over the reach with an abrupt change to $n_{0}=0.045$ at the downstream cross-section. 
Table 1 shows what is intuitively expected for a reach without any sudden changes in channel properties: by letting $n$ assume noninteger values, simulations improve, but there is no additional improvement by letting the last stor- age element have a storage property independent of the rest of the cascade. This is so because the channel is homogeneous in every respect (roughness parameter, channel slope); thus the storage delay time, $k^{-1}$, is expected to be

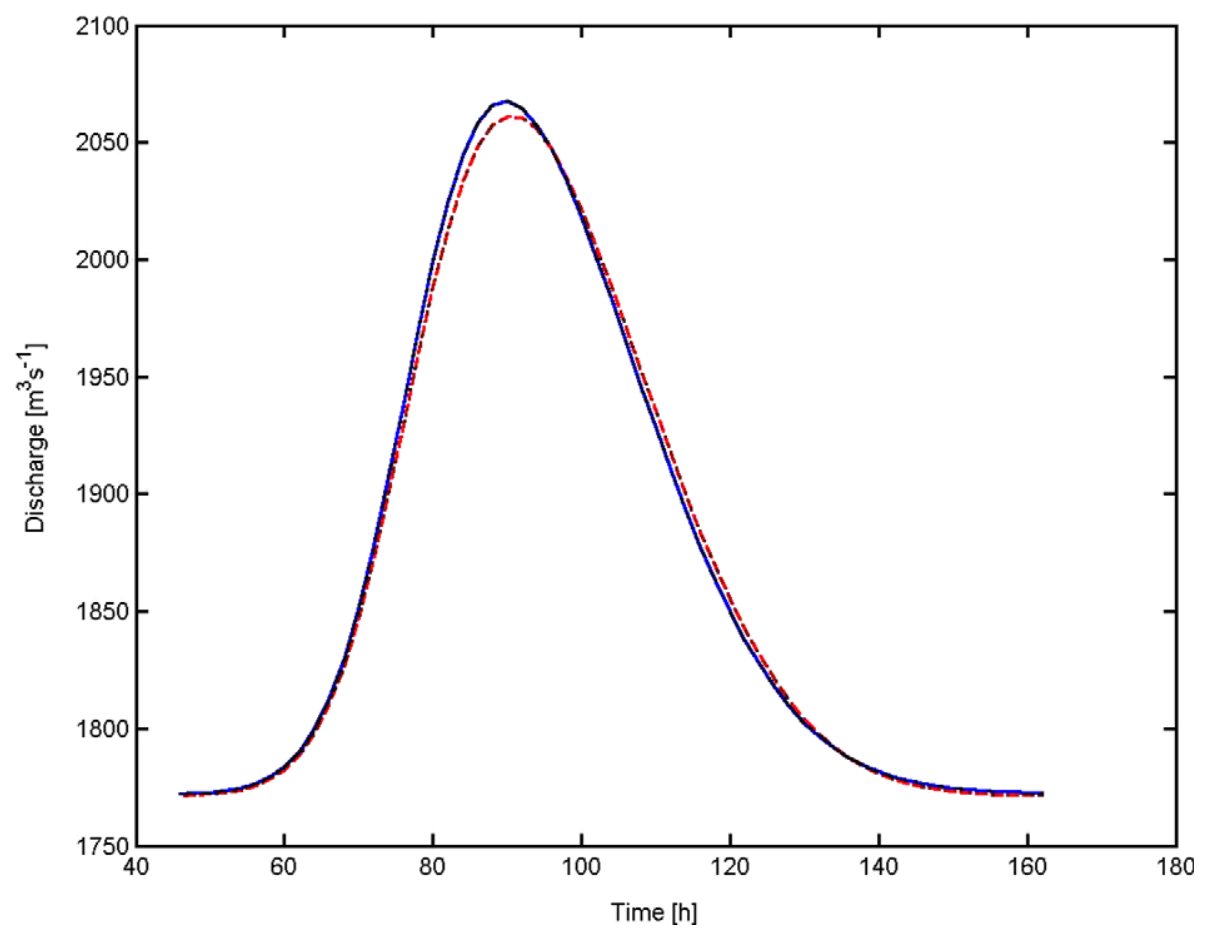

Figure 4 Discharge hydrographs at $x=1000 \mathrm{~km}$, provided by the Saint-Venant equations. Solid line corresponds to the constant $n_{0}$ case.

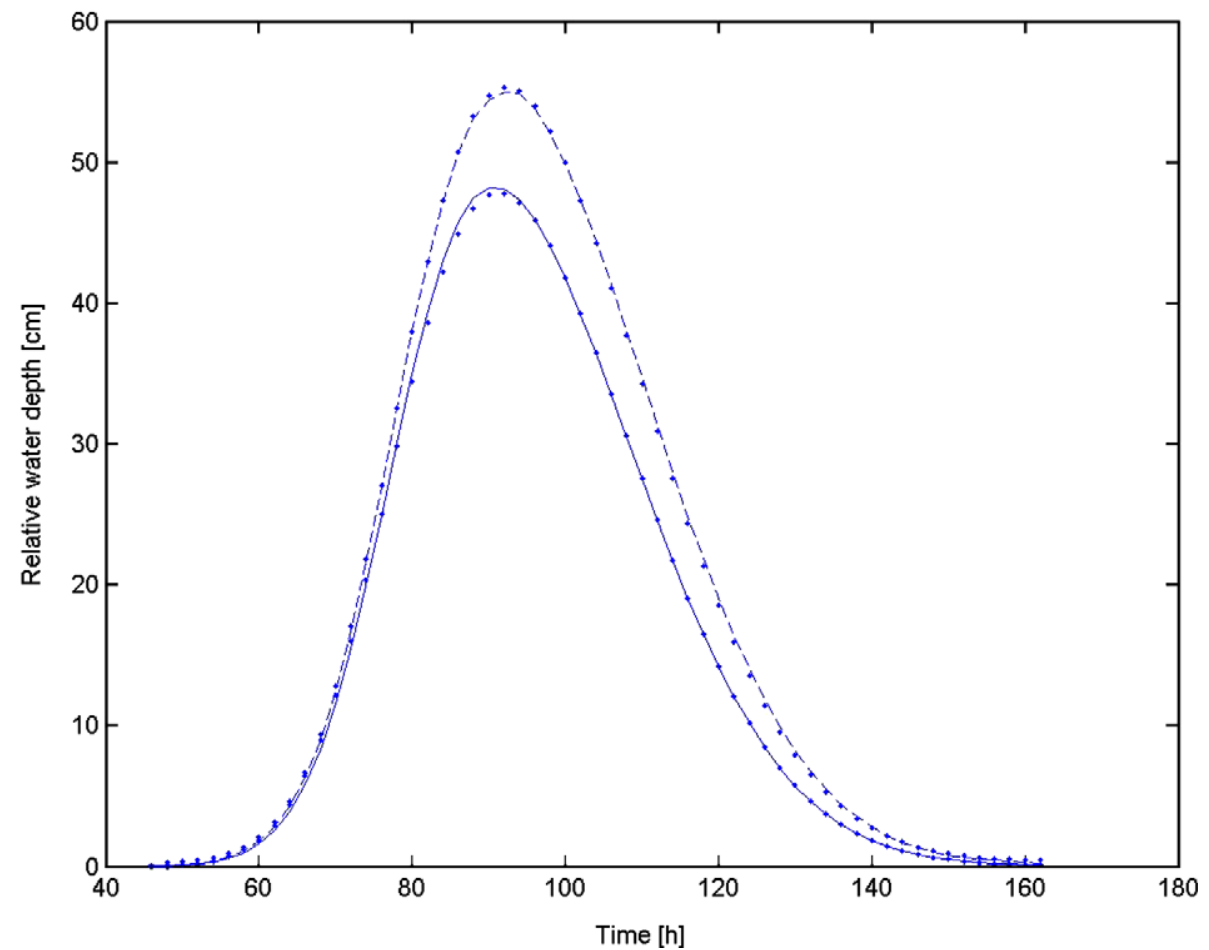

Figure 5 Stage hydrographs at $x=1000 \mathrm{~km}$, provided by the Saint-Venant equations. Solid line corresponds to the constant $n_{0}$ case. Depth is relative to the initial normal depth (i.e. 500 and $579 \mathrm{~cm}$, respectively). The dots are the results of the fully nonuniform cascade simulations. 
identical for each linear storage element and proportionally smaller for the last fractional element.

In the second stage of the numerical experiments, the channel had two different roughness coefficient values: $n_{0}=0.035$ over the first $1000 \mathrm{~km}$ of the channel, and $n_{0}=$ 0.045 for the rest of it (Fig. 2). As Table 1 and Fig. 3 show, model results improve again by switching from an integer $n$ -cascade to a fractional $n$-cascade. When letting the last storage element assume an arbitrary storage coefficient (i.e. independent of the rest of the cascade), the routed values improve, although slightly. Note that the optimized value of $k_{x}\left(=0.35 \mathrm{~h}^{-1}\right)$ of the last storage element is indeed smaller than the storage coefficient value, $k\left(=0.785 \mathrm{~h}^{-1}\right)$, for the uniform part of the cascade, meaning that now the last storage element is slower than the rest, and so having an increased storage delay time, i.e. $k_{x}^{-1} \approx 2.86 \mathrm{~h}$ vs. $k^{-1}=$ $1.27 \mathrm{~h}$.

Table 1 suggests that the model accuracy is significantly better in the presence of a sudden change in channel properties, but this is only true for discharges. The discharge flood hydrograph is more diffuse (i.e. flatter, see Fig. 4) for the inhomogeneous channel case, thus causing a seemingly increased model accuracy. This, however, is not the case for stages. With the flow velocity slowed down where the value of the roughness parameter increases abruptly, any change in the flowrate value becomes magnified (Fig. 5) in the corresponding stage values.

To prove this, the stage values pairing with the modeled flowrate values were estimated through the application of the Jones formula (1916)

$$
Q=Q_{0} \sqrt{1+\frac{1}{S_{0} c_{k}} \frac{\partial h}{\partial t}}
$$

where $Q_{0}$ is the flowrate at stage $h$ for permanent flow, and $c_{\mathrm{k}}$ is the kinematic wave celerity (a function of $h$ ). Eq. (30) is an implicit expression for $h$ now, when discharge is specified. From Eq. (29), employing $R \approx h$, the $Q_{0}(h)$ relationship can be specified (Fig. 6), where the effective value $\left(n_{0}^{*}\right)$ of $n_{0}$ had to be optimized for the abruptly changing case. The $c_{\mathrm{k}}(h)$ relationship results from Eq. (29), using the $R \approx h$ approximation, and combining it with the Kleitz-Seddon law, which for the wetted cross-sectional area, $A(h)$, of a rectangular channel can be written as

$c_{\mathrm{k}}(h)=\frac{\partial Q_{0}}{\partial A}=\frac{1}{B} \frac{\partial Q_{0}}{\partial h}=\frac{5}{3} \frac{\sqrt{S_{0}}}{n_{0}^{*}} h^{2 / 3}$.

Fig. 5 displays the so-derived stage values of flow routing using the fully nonuniform cascades, in comparison with the Saint-Venant equation values. The MRSE values for the constant and changing $n_{0}$ cases are: $0.31 \mathrm{~cm}$ and $0.28 \mathrm{~cm}$, respectively (almost the same), thus proving our assertion above.

In conclusion, the following can be stated: With discrete data, the continuous Kalinin-Milyukov-Nash cascade of equal reservoirs of noninteger order $n$ can be approximated by a cascade of int $(n)$ equal reservoirs followed by an element having a storage coefficient of $k_{x}=k[n-\operatorname{int}(n)]^{-1}$, in a state-space formulation. Near sudden changes in channel properties, the storage coefficient of the last reservoir, $k_{x}$, can be specified independently of that of the rest of the cascade.
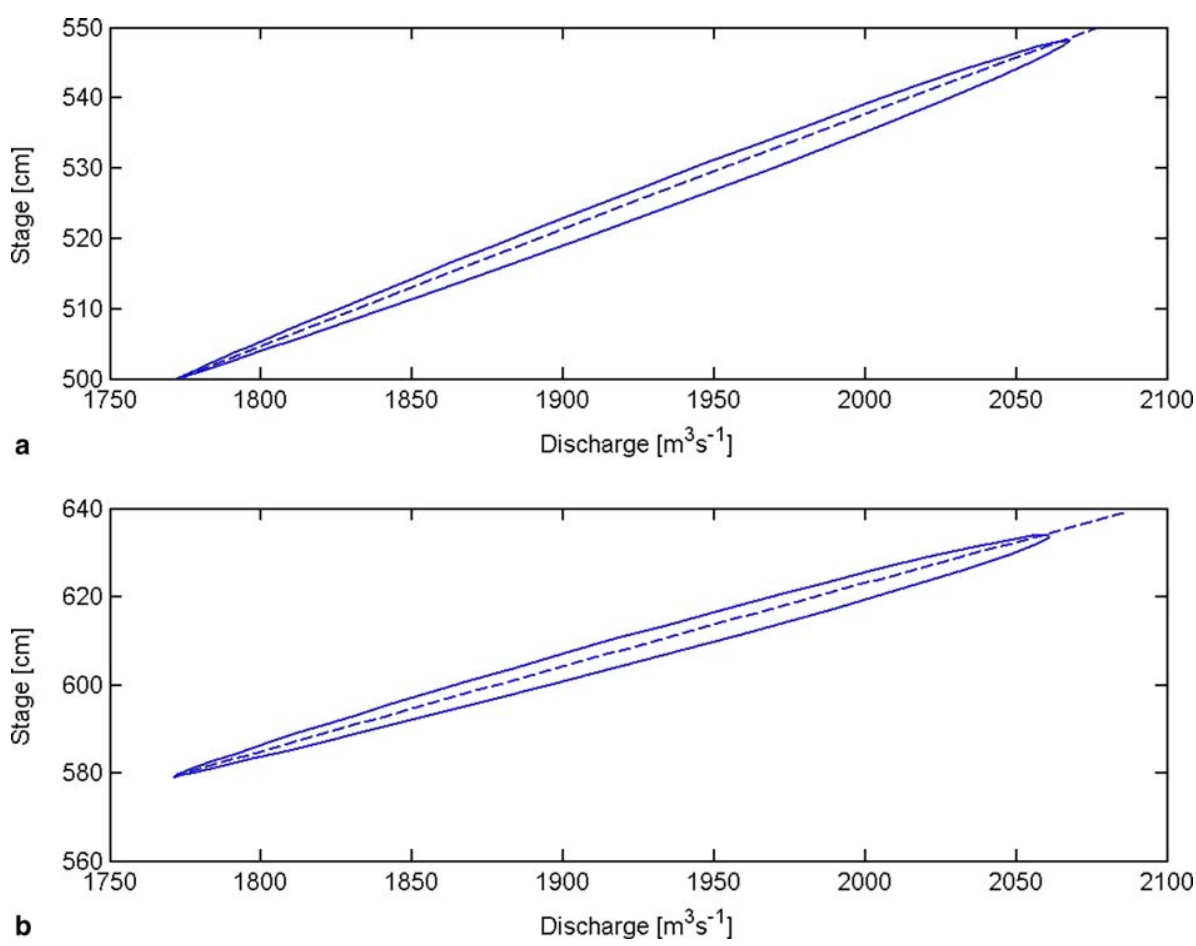

Figure 6 Discharge-stage relationships (i.e. loop rating curves) at $x=1000 \mathrm{~km}$ from the Saint-Venant equations with the corresponding estimated permanent rating curves (intermittent lines): (a) constant $n_{0}$ case and (b) changing $n_{0}$ case, with $n_{0}^{*}=0.04475$. 


\section{Acknowledgements}

The author is grateful to Charles Flowerday for his editorial comments on an earlier version of the manuscript and to the two anonymous reviewers whose comments have led to significant improvements. A contribution of the University of Nebraska Agricultural Research Division, Lincoln, NE 68583. Journal Series No. 15091.

\section{References}

Abramowitz, M., Stegun, I.A., 1972. Handbook of Mathematical Functions. Dover, New York.

Camacho, L.A., Lees, M.J., 1999. Multilinear discrete lag-cascade model for channel routing. J. Hydrol. 226, 30-47.

Chow, V.T., Maidment, D.R., Mays, L.W., 1988. Applied Hydrology. McGraw-Hill, New York.

Dooge, J.C.I., 1973. Linear theory of hydrologic systems. USDA Tech. Bull. No., 1468.

Dooge, J.C.I., O'Kane, J.P., 2003. Deterministic Methods in Systems Hydrology. A.A. Balkema, Lisse.

Hantush, M.M., Harada, M., Marino, M.A., 2002. Hydraulics of streamflow routing with bank storage. J. Hydrol. Eng. 7 (1), $76-$ 89.

Henderson, F.M., 1966. Open Channel Flow. MacMillan, New York.

Jones, B.E., 1916. A Method for Correcting River Discharge for a Changing Stage. USGS Water Supply Paper No. 375-E, US Geological Survey, Washington, DC.

Kalinin, G.P., Milyukov, P.I., 1957. O raschete neustanovivshegosya dvizheniya vody $v$ otkrytykh ruslakh (On the computation of unsteady flow in open channels). Met. i Gydrologia Zhurnal 10, 10-18.

Kalinin, G.P., Milyukov, P.I., 1958. Priblizheniy raschete neustanoviv-shegosya dvizheniya vodnyh mas (Approximation of unsteady flow)Trudi CIP, 66. Leningrad.

Kalman, R.E., 1960. A new approach to linear filtering and prediction problems. ASME J. Basic Eng. 82D, 35-45.

Keefer, T.N., McQuivey, R.S., 1974. Multiple linearisation flow routing model. ASCE J. Hydraul. Div. 100 (7), 1031-1046.
Kontur, I., 1977. A lefolyas altalanos linearis kaszkad modellje (General linear cascade model of runoff, in Hungarian). Hidrologiai Kozlony 9, 404-412.

Kundzewicz, Z.W., Dooge, J.C.I., 1985. Unified structural approach to linear flood routing. Adv. Water Resour. 8, 37-43.

Nash, J.E., 1957. The form of instantaneous unit hydrograph. Int. Assoc. Sci. Hydrol. Publ. 45 (3), 114-121.

O'Connor, K.M., 1976. A discrete linear cascade model for hydrology. J. Hydrol. 29, 203-242.

Perumal, M., 1994. Multilinear discrete cascade model for channel routing. J. Hydrol. 158, 135-150.

Szilagyi, J., 2004. Accounting for stream-aquifer interactions in the state-space discretization of the Kalinin-Milyukov-Nash cascade for streamflow forecasting. J. Hydrol. Eng. 9 (2), 135-143.

Szilagyi, J., 2003. State-space discretization of the Kalinin-Milyukov-Nash cascade in a sample-data system framework for streamflow forecasting. J. Hydrol. Eng. 8 (6), 339-347.

Szilagyi, J., Balint, G., Gauzer, B., Bartha, P., 2005. Flow routing with unknown rating curves using a state-space reservoircascade-type formulation. J. Hydrol. 311, 219-229.

Szolgay, J., 1991. Prediction of River Runoff Changes due to Hydropower Development on the Danube at Gabcikovo, IAHS Publication No. 201, pp. 209-218.

Szolgay, J., 2004. Multilinear discrete cascade model for river flow routing and real-time forecasting in river reaches with variable wave speed. In: Brath, A. (Ed.), Hydrological risk: recent advances in peak river flow modelling, prediction and real-time forecasting - assessment of the impact of land-use and climate changes. BIOS, Castrolibero.

Szollosi-Nagy, A., 1976. Introductory remarks on the state-space modeling of water resource systems. IIASA, Laxemburg, Res. Mem. 76 (73).

Szollosi-Nagy, A., 1981. State Space Models of the Nash-cascade, Kinematic and Diffusion Waves. University of Lulea, Research Report TULEA, p. 14.

Szollosi-Nagy, A., 1982. The discretization of the continuous linear cascade by means of state space analysis. J. Hydrol. 58, 223-236.

Szollosi-Nagy, A., 1989. A mederbeli lefolyas real-time elorejelzése dinamikus strukturalis-sztochasztikus modellekkel (Real-time Stream-flow Forecasting Using Dynamically Structured Deterministic-stochastic Models). VITUKI, Budapest. 